УДК 54.05

\title{
ИЗУЧЕНИЕ СТРОЕНИЯ ПРОДУКТОВ СУЛЬФАТИРОВАНИЯ МИКРОКРИСТАЛЛИЧЕСКОЙ ЦЕЛЛЮЛОЗЫ ХЛОРСУЛЬФОНОВОЙ КИСЛОТОЙ В ДИОКСАНЕ МЕТОДАМИ КР, РФА, РЭМ И АСМ
}

\author{
() Б.Н. Кузнецов ${ }^{1,2 *}$, В.А. Левданский ${ }^{1,2}$, А.С. Крылов ${ }^{3}$, А.В. Левданский, Г.Н. Бондаренко ${ }^{I}$, \\ А.С. Романченко ${ }^{1}$, E.В. Мазурова ${ }^{l}$ \\ ${ }^{1}$ Институт химии и химической технологии СО РАН, Академгородок, 50-24, \\ Красноярск 660036 (Россия), e-mail: inm@icct.ru \\ ${ }^{2}$ Сибирский федеральный университет, пр. Свободный, 79, Красноярск, \\ 660041 (Россия) \\ ${ }^{3}$ Институт фризики им. Киренского СО РАН, Академгородок, 50-38, \\ Красноярск, 660036 (Россия)
}

\begin{abstract}
Выполнено физико-химическое исследование строения сульфатированной микрокристаллической целлюлозы (МКЦ), полученной окислительной делигнификацией соломы пшеницы. Методом спектроскопии комбинационного рассеяния установлено замещение ОН-групп МКЦ на сульфатные при взаимодействии МКЦ с хлорсульфоновой кислотой в диоксане. Методом рентгеновской дифрактометрии показано, что в процессе сульфатирования МКЦ снижается степень ее кристалличности. По данным растровой электронной микроскопии и атомно-силовой микроскопии сульфаты МКЦ, полученные в среде диоксана, имеют морфологию, полностью отличную от исходной МКЦ. Они состоят из частиц сферической формы, причем поверхность пленки сульфатов МКЦ сформирована однородными сферическими кристаллитами размером 100-150 нм.

Ключевые слова: микрокристаллическая целлюлоза, хлорсульфоновая кислота, диоксан, сульфаты МКЦ, спектроскопия КР, рентгеновская дифрактометрия, растровая электронная микроскопия, атомно-силовая микроскопия.

Работа выполнена при финансовой поддержке РФФИ (проекты № 12-03-31433 и № 12-03-93117) и ККФПНиНТД (дополнительное соглашение № 07/12 от 04.09.2012).
\end{abstract}

Кузнеиов Борис Николаевич - заведующий лабораторией, профессор, доктор химических наук, заведующий кафедрой, тел.: (391) 249-48-94, e-mail: bnk@icct.ru

Левданский Владимир Александрович - ведущий научный сотрудник, доцент, доктор химических наук, тел.: (391)249-55-84, e-mail: lva@ icct.ru Крылов Александр Сергеевич - научный сотрудник, кандидат химических наук, тел.: (391) 249-45-10, e-mail: shusy@iph.krasn.ru

Левданский Александр Владимирович - научный сотрудник, кандидат химических наук, тел.: (391) 249-55-84, e-mail: alexsander.1@ mail.ru Бондаренко Галина Николаевна - научный сотрудник, кандидат химических наук, тел.: (391) 249-47-34, e-mail: gal@ ksc.krasn.ru

Романченко Александр Сергеевич - научный сотрудник, кандидат химических наук, тел.: (391) 249-48-85, e-mail: romaas82@mail.ru Мазурова Елена Валентиновна - научный сотрудник, кандидат технических наук, тел.: (391) 249-55-87, e-mail: kargin@icct.ru

\section{Введение}

Известно, что сульфаты целлюлозы (СЦ) проявляют антикоагулянтную активность, уровень которой зависит от способа получения исходной целлюлозы и условий ее сульфатирования [1].

Существующие методы получения сульфатов целлюлозы имеют целый ряд недостатков: они сложны, продолжительны, многостадийны, используют токсичные реагенты, причем образуются загрязненные сульфатированные продукты, требующие дополнительной очистки диализом [2-5]. Поскольку сульфатирование целлюлозы, как правило, осуществляется в двухфазной системе, образуются неоднородные по химическому составу сульфаты целлюлозы [6].

В работе [7] предложено использовать ионные жидкости для гомогенного сульфатирования

\footnotetext{
*Автор, с которым следует вести переписку.
} 
целлюлозы. Сульфатирование осуществляли комплексом хлорсульфоновой кислоты и диметилформамида в ионном растворителе 1-бутил-3-метилимидазолиум хлорида $\left([\mathrm{C} 4 \mathrm{mim}]^{+} \mathrm{Cl}^{-}\right)$при $30^{\circ} \mathrm{C}$. Степень замещения СЦ составляла 0,52-2,95, причем осуществлялось сульфатирование ОН-групп при С6, С2 и С3 атомах углерода глюкопиранозных звеньев. К недостаткам данного метода следует отнести длительное растворения целлюлозы в $[\mathrm{C} 4 \mathrm{mim}]^{+} \mathrm{Cl}^{-}$.

Нами было установлено, что реакция сульфатирования МКЦ хлорсульфоновой кислотой в диоксане начинается в двухфазной, а заканчивается в однофазной системе практически полным сульфатированием $\mathrm{OH}$ групп при С6 атомах глюкопиранозных звеньев [8]. С помощью ИК и ЯМР ${ }^{13} \mathrm{C}$ спектроскопии проведено исследование строения и антикоагулянтных свойств сульфатированных производных МКЦ. Показано, что полученные сульфаты целлюлозы являются антикоагулянтами прямого действия и удлиняют время свертывания плазмы человека in vitro в коагулологических тестах [9].

С целью установления взаимосвязи между строением и биологической активностью сульфатированных производных МКЦ, полученных новым способом, в настоящей работе проведено их дополнительное физико-химическое исследование с применением методов спектроскопии комбинационного рассеяния, рентгеновской дифрактометрии, растровой электронной микроскопии и атомно-силовой микроскопии.

\section{Экспериментальная часть}

В качестве исходного сырья для получения МКЦ использовали солому пшеницы, собранную на полях Емельяновского района Красноярского края. Химический состав исходного сырья представлен в таблице 1.

Растительное сырье измельчали до частиц размером 1-2 мм и высушивали при $105{ }^{\circ} \mathrm{C}$ в течение 6-8 ч до влажности менее $1 \%$. Химический анализ сырья проводили по стандартным методикам [10].

Получение образцов микрокристаллической целлюлозы осуществляли экологически безопасным способом - окислительной делигнификацией соломы пшеницы пероксидом водорода в среде уксусная кислота - вода в присутствии сернокислотного катализатора по методикам, описанным в работе [11]. Некоторые характеристики использованных образцов МКЦ приведены в таблице 2.

Получение сульфатов целлюлозы осуществляли по методике [8] сульфатированием МКЦ хлорсульфоновой кислотой в диоксане с последующим выделением сульфата целлюлозы в виде натриевой соли. Прозрачные плёнки сульфатированных образцов МКЦ получали испарением 6-7\%-ных водных растворов на гладкой стеклянной подложке.

КР-спектры образцов были сняты на Bruker RFS 100/S спектрометре с охлаждаемым жидким азотом $\mathrm{Ge}$ диодом в качестве детектора. В качестве источника света для возбуждения рамановского рассеяния применялся $\mathrm{Cw}-\mathrm{Nd}$ : YAG лазер с возбуждающей линией 1,064 нм. КР-спектры были записаны в диапазоне 100-3500 $\mathrm{cm}^{-1}$, используя рабочее спектральное разрешение $2 \mathrm{~cm}^{-1}$. Выходная мощность лазера составляла $100 \mathrm{~mW}$. Каждый образец был дважды проанализирован при одинаковых условиях, и было накоплено 400 разверток. Усредненный спектр был сформирован как окончательный спектр соответствующего образца, была выполнена векторная нормировка спектра.

Интегрирование пиков было выполнено с помощью операционного спектроскопического программного обеспечения OPUS Ver. 6.0 (Bruker Optik GmbH, Эттлинген Германия). Анализ данных был выполнен с помощью OriginPro 7.0 (OriginLab Corporation, Массачусетс США).

Рентгенофазовый анализ проведен на рентгеновском дифрактометре ДРОН-3 с использованием Сu $\mathrm{K} \alpha$ монохроматизированного излучения $(\lambda=0,154$ нм), напряжение $\mathrm{U} 32 \mathrm{\kappa B}$, сила тока 24 мА. Скорость углового перемещения образца относительно первоначального направления луча составляла 1 град./мин. Съемку проводили в интервале брэгговских углов $2 \Theta$ от 5,00 до 50,00 град.

Таблица 1. Химический состав соломы пшеницы

\begin{tabular}{c|c|c|c|c}
\hline \multicolumn{5}{c}{ Состав, \% от массы а.с. сырья } \\
\hline Целлюлоза & Лигнин & Гемицеллюлозы & Экстрактивные вещества & Зольность \\
\hline 48,7 & 21,4 & 23,2 & 2,6 & 4,1 \\
\hline
\end{tabular}

Таблица 2. Характеристики МКЦ из соломы пшеницы

\begin{tabular}{c|c|c|c}
\hline $\begin{array}{c}\text { Степень полимеризации } \\
(\text { СП) }\end{array}$ & $\begin{array}{c}\text { Степень кристалличности } \\
(\text { СК })\end{array}$ & $\begin{array}{c}\text { Содержание остаточного лиг- } \\
\text { нина, } \%\end{array}$ & $\begin{array}{c}\text { Содержание гемицел- } \\
\text { люлоз, \% }\end{array}$ \\
\hline 200 & 0,66 & 0,1 & 5,5 \\
\hline
\end{tabular}


Индекс кристалличности образцов МКЦ из соломы пшеницы, показывающий долю кристаллической части в образце целлюлозы, рассчитывали на основании рентгенограмм - вычитанием фонового рассеивания из всей кривой. Полученное для этих образцов значение $(0,66)$ близко к значениям индексов кристалличности промышленной МКЦ $(0,64-0,80)$.

Электронные микрофотографии получены на растровом электронном микроскопе ТМ-1000 HITACHI (Япония) с ускоряющим напряжением $15 \mathrm{kV}$ и с увеличением от 100 до 10000 крат с разрешением 30 нм.

Исследования пленок сульфатированной МКЦ методом атомно-силовой микроскопии (АСМ) проводились на сканирующем зондовом мультимодовом микроскопе Solver P47 (НТ-МДТ, Москва), укомплектованным 14 мкм сканером (сканирование образцом). Исследования проводились при комнатной температуре на воздухе. В качестве зондов в полуконтактной моде АСМ применялись поставляемые производителем микроскопа кремниевые кантилеверы с константой жесткости около 6 Н/м. Сканирование производилось не менее чем в 3-4 точках на нескольких параллельно обработанных образцах. Скорость сканирования составляла 1-2 Гц, число точек на сканируемой площадке было 256 на 256 либо 512 на 512. Как правило, сглаживания или иной обработки изображений не проводилось.

\section{Результаты и обсуждение}

В развитие ранее выполненного исследования по сульфатированию микрокристаллической целлюлозы из соломы пшеницы, хлорсульфоновой кислотой в диоксане, изучено строение натриевых солей полученных сульфатов МКЦ методами КР, РФА, РЭМ и АСМ.

Результаты исследований методом КР-спектроскопии образцов МКЦ, а также продуктов сульфатирования МКЦ хлорсульфоновой кислотой в диоксане, совпадают с данными, приведенными в работах [12, 13].

Введение сульфатной группы в структуру целлюлозы подтверждается появлением в КР-спектрах натриевых солей сульфатированных образцов МКЦ новых полос поглощения в областях 417-420, 588-590, 840-845, 1073-1075, 1269-1279 $\mathrm{cm}^{-1}$ (рис. 1).

Полоса поглощения в области 417-420 $\mathrm{cm}^{-1}$ соответствует деформационным колебаниям $\mathrm{SO}_{3}$ групп $\delta\left(\mathrm{SO}_{3}\right)$, а полоса при 588-590 см-1 может быть отнесена к деформационным колебаниям $\delta(\mathrm{O}=\mathrm{S}=\mathrm{O})$. Полоса поглощения в области 840-845 cм с $^{-1}$ соответствует C-O-S валентным колебаниям v(C-O-S). Полоса поглощения в диапазоне 1073-1075 $\mathrm{cm}^{-1}$ доминирует в спектре и присуща симметричным валентным колебаниям $v_{\mathrm{s}}(\mathrm{O}=\mathrm{S}=\mathrm{O})$. Другой пик при 1269-1279 см$^{-1}$ является сигналом ассиметричных валентных колебаний $v_{\mathrm{as}}(\mathrm{O}=\mathrm{S}=\mathrm{O})$.

Интенсивные полосы в областях 1095-1096, 1121, 1148-1152 см-1 присущие валентным (полносимметричным) колебаниям цикла и симметричным валентным колебаниям гликозидных связей $v_{\mathrm{s}}(\mathrm{COC})$ наблюдаются в исходной МКЦ, однако в сульфатированных образцах из-за введения сульфатных групп их интенсивности снижаются, и наблюдается только один слабый сигнал с максимумом при 1120-1124 см-1.

Кроме того, в результате замещения атомов водорода в гидроксильных группах на сульфатные изменяются интенсивности пиков валентных колебаний $\mathrm{CH}$ и $\mathrm{CH}_{2}$ групп. Так в спектре исходной МКЦ в области $2894 \mathrm{~cm}^{-1}$ наблюдается доминирующий пик, относящийся к валентным колебаниям СН групп, но после сульфатирования его интенсивность падает и в области 2961-2966 см${ }^{-1}$ появляется новый пик валентных колебаний $\mathrm{CH}_{2}$ групп.

Рис. 1. КР-спектры образцов: а - исходной МКЦ; 1, 2 - сульфатированных образцов МКЦ

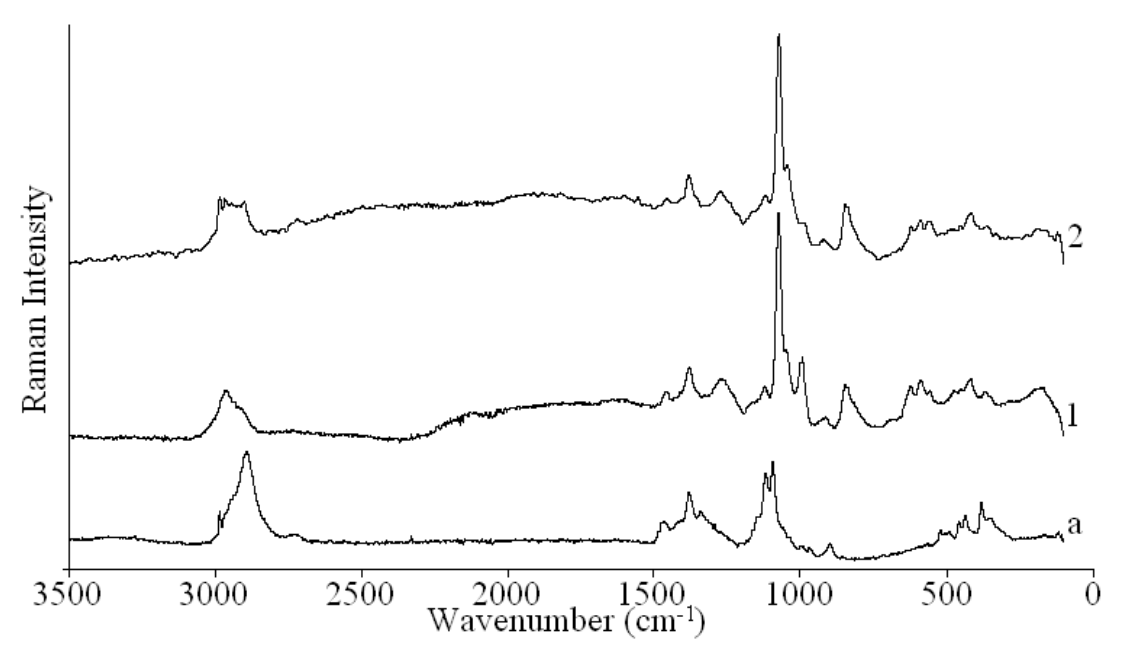


Образцы МКЦ, полученные из соломы пшеницы, обладают высокой степенью упорядоченности. Об этом свидетельствуют наличие на рентгенограмме (рис. 2a) максимума в области $2 \Theta=22$, характерного для МКЦ [14] и для хлопковой целлюлозы [15].

Сульфатирование целлюлозы с использованием традиционных методов приводит к ее частичной деполимеризации [2, 3]. Повышение температуры сульфатирования порошковой целлюлозы хлорсульфоновой кислотой в абсолютном пиридине слабо отражается на увеличении степени замещения, однако при этом выход сульфатированного производного уменьшается из-за усиления деструкции целлюлозного полимера [16]. Сопоставление рентгенограмм образцов исходной МКЦ и сульфатированной хлорсульфоновой кислотой в диоксане, показало, что в процессе сульфатирования происходит снижение степени кристалличности МКЦ (рис. 2б).

По данным метода растровой электронной микроскопии исходная МКЦ состоит из различных по длине микрофибрилл с толщиной около 10-25 мкм (рис. 3). Некоторые микрофибриллы собраны в агрегаты - пакеты длиной около 75-500 мкм и шириной 30-150 мкм. После сульфатирования образцы имеют морфологию, полностью отличную от исходной МКЦ. Сульфатированная МКЦ состоит из частиц с диаметром от 1,5 до 0,1 мкм (и меньше), а микрофибриллы полностью отсутствуют. Частицы имеют компактную форму, близкую к сферической.

Проведен анализ методом атомно-силовой микроскопии (АСМ) прозрачной пленки, приготовленной из сульфатированной МКЦ соломы пшеницы (рис. 4).

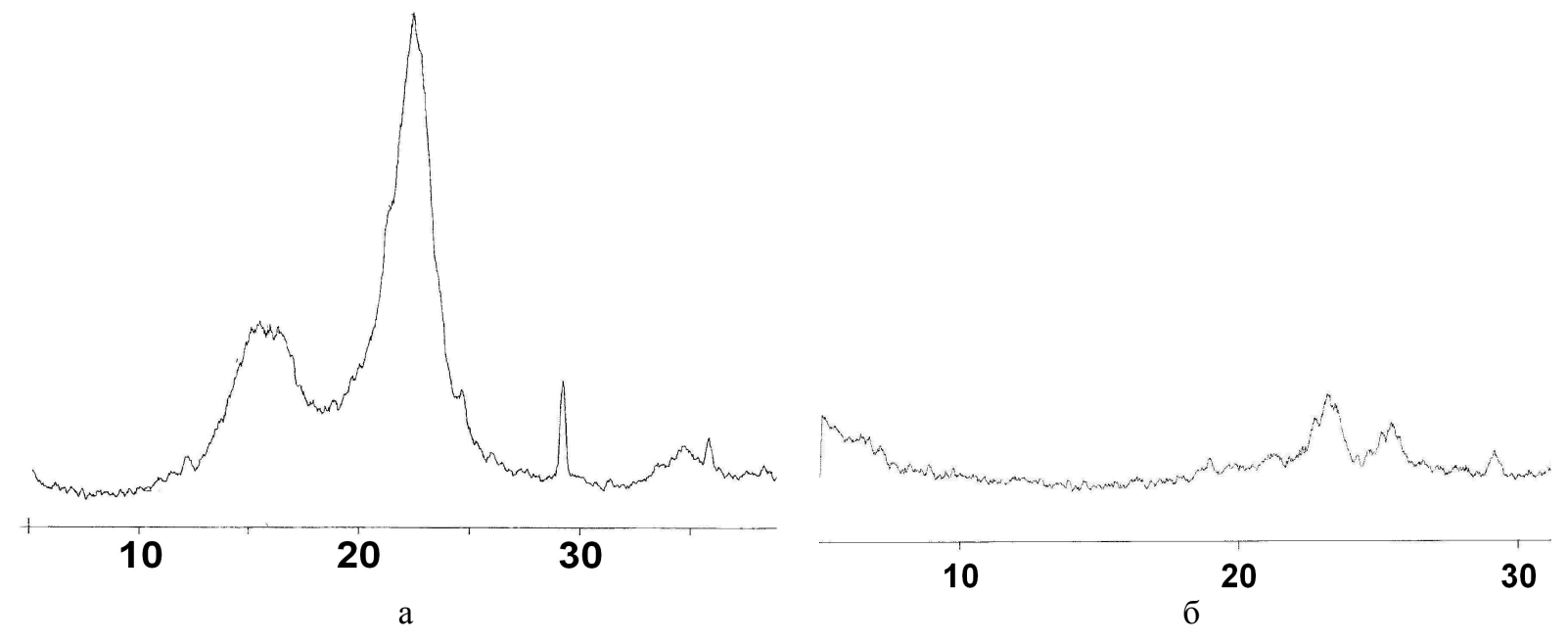

Рис. 2. Рентгенограммы образцов исходной (а) и сульфатированной (б) МКЦ

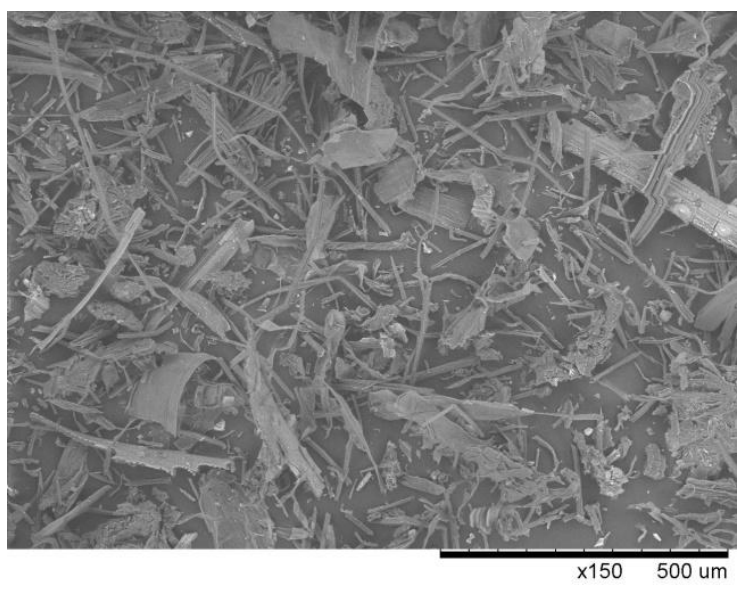

a

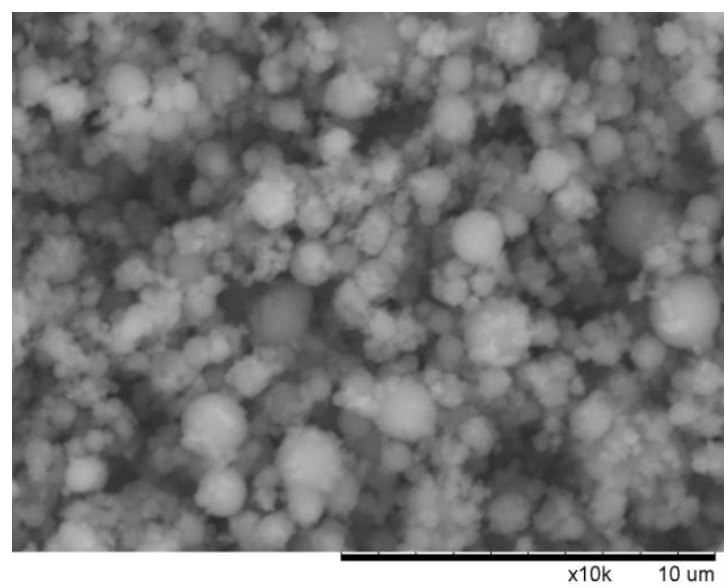

6

Рис. 3. РЭМ изображения образцов исходной МКЦ (а) и сульфатированной МКЦ (б) 


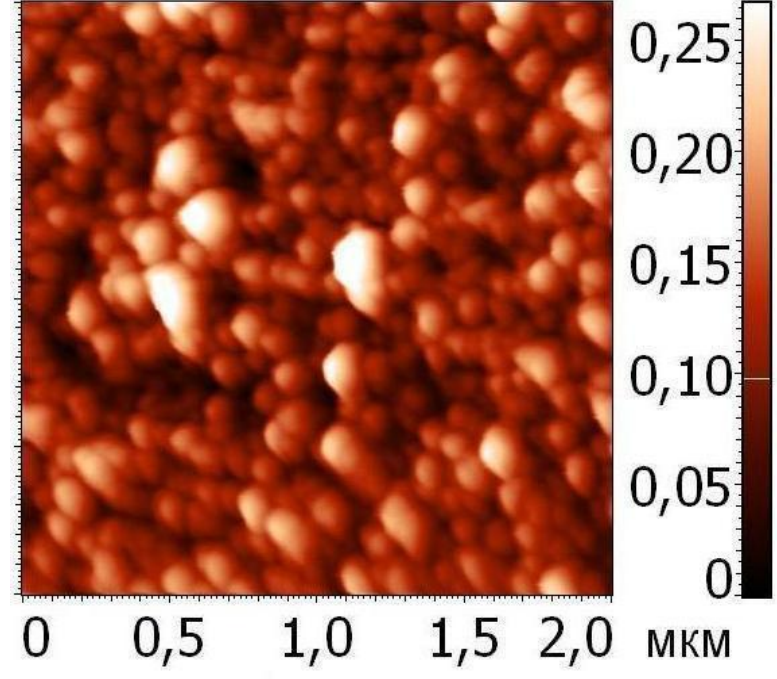

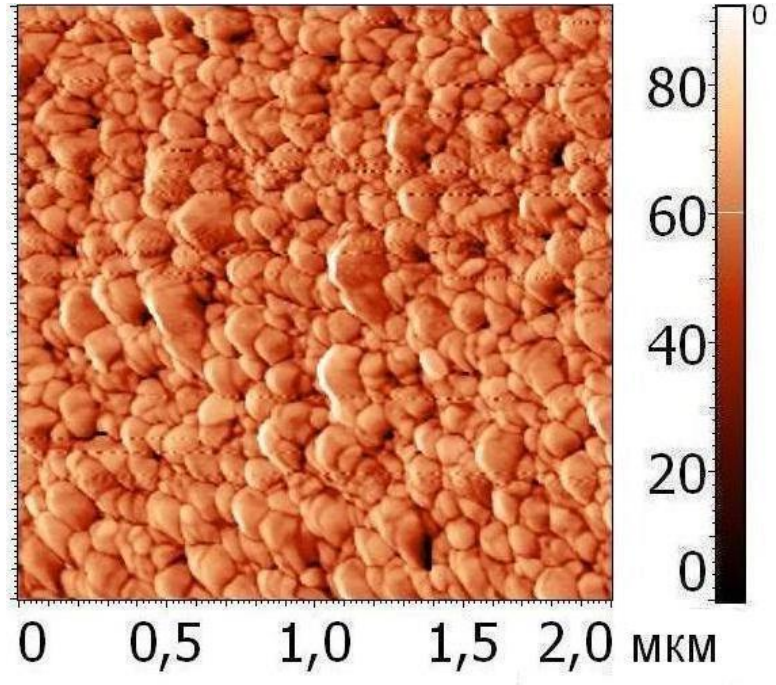

б

Рис. 4. АСМ изображение пленки сульфатированного образца МКЦ (а - рельеф, б - фазовый контраст)

Как видно на рисунке 4, поверхность сульфатированной МКЦ соломы пшеницы состоит из однородных кристаллитов, имеющих сферическую форму и размеры порядка 100-150 нм. Судя по изображению фазового контраста, инородных включений на поверхности пленки не обнаружено.

Сравнение с результатами ранее выполненного исследования методами РЭМ и АСМ строения сульфатов МКЦ из древесины осины, полученных аналогичным методом [17], показывает, что размер и форма частиц сульфатированной МКЦ мало зависят от природы исходного сырья, используемого для получения МКЦ.

Высокая однородность продуктов сульфатирования МКЦ хлорсульфоновой кислотой в диоксане обусловлена тем, что реакция начинается в двухфазной, а заканчивается в однофазной среде. Традиционная реакция сульфатирования МКЦ хлорсульфоновой кислотой в пиридине начинается и заканчивается в двухфазной среде [3], что затрудняет получение однородных по составу и морфологии продуктов.

\section{Bblвodbl}

Методами КР, РФА, РЭМ и АСМ установлено строение сульфатов микрокристаллической целлюлозы, полученных новым способом - сульфатированием МКЦ из соломы пшеницы хлорсульфоновой кислотой в диоксане.

При сульфатировании МКЦ снижается степень ее кристалличности и кардинально изменяется морфология МКЦ, изначально состоящей из микрофибрил и агрегатов микрофибрил. Полученные сульфаты МКЦ представлены частицами сферической формы. Поверхность пленки сульфатов МКЦ характеризуется наличием однородных сферических кристаллитов размером 100-150 нм.

Высокая однородность продуктов сульфатирования МКЦ хлорсульфоновой кислотой в диоксане обусловлена формированием однофазной реакционной среды в процессе сульфатирования.

\section{Благодарности}

В работе использованы приборы Красноярского регионального центра коллективного пользования СО РАН. Авторы выражают благодарность В.Ф. Каргину за содействие в регистрации и интерпретации данных растровой электронной микроскопии.

\section{Список литературы}

1. Groth T., Wagenknecht W. Anticoagulant potential of regioselective derivatized cellulose // Biomaterials. 2001. Vol. 22. Issue 20. Pp. 2719-2729.

2. Петропавловский Г.А. Гидрофильные частично замещенные эфиры целлюлозы и их модификация путем химического сшивания. Л., 1988. 298 с.

3. Торлопов М.А, Демин В.А. Сульфатированные и карбоксиметилированные производные микрокристаллической целлюлозы // Химия растительного сырья. 2007. № 3. С. 55-61. 
4. Mahner C., Lechner M.D., Nordmeier E. Synthesis and characterization of dextran and pullan sulphate // Carbohydrate Research. 2001. Vol. 331. Pp. 203-208.

5. Wang Z.M., Li L, Zheng B.S., Normakhamatov N., Guo S.Y. Preparation and anticoagulation activity of sodium cellulose sulfate // Int. J. Biol. Macromol. 2007. Vol. 41(4). Pp. 376-382.

6. Роговин 3.А., Шорыгина Н.Н. Химия целлюлозы и ее спутников. М., 1953. 680 с.

7. Wang, Z.M., Li L., Xiao K.-J., Wu J.-Y. Homogeneous sulfation of bagasse cellulose in an ionic liquid and anticoagulation activity // Bioresource Technology. 2009. Vol. 100. N 4. Pp. 1687-1690.

8. Левданский В.А., Левданский А.В., Кузнецов Б.Н. Сульфатирование микрокристаллической целлюлозы хлорсульфоновой кислотой в диоксане // Химия растительного сырья. 2012. № 1. С. 39-44.

9. Калинина Т.Б., Дрозд Н.Н., Кузнецова С.А. и др. Влияние структурных параметров сульфата целлюлозы, выделенной из соломы Triticum aestivum L., на антикоагулянтную активность // Гематология и трансфузиология. 2011. Т. 56. № 6. С.33-38.

10. Оболенская А.В., Ельницкая 3.П., Леонович А.А. Лабораторные работы по химии древесины и целлюлозы: учебное пособие для вузов. М., 1991. 320 с.

11. Патент 2312110 (РФ). Способ получения микрокристаллической целлюлозы из соломы злаковых / Б.Н. Кузнецов, В.Г. Данилов, О.В. Яценкова, Е.Ф. Ибрагимова. 10.12.2007.

12. Zhang K., Brendler E., Fischer S. FT Raman investigation of sodium cellulose sulfate // Cellulose. 2010. Vol. 17, N 2. Pp. 427-435.

13. Zhang K., Brendler E., Geissler A., Fischer S. Synthesis and spectroscopic analysis of cellulose sulfates with regulable total degrees of substitution and sulfation patterns via 13C NMR and FT Raman spectroscopy // Polymer. 2011. Vol. 52. N 1. Pp. 26-32.

14. Баттиста О.А. Микрокристаллическая целлюлоза // Целлюлоза и ее производные / под ред. Н. Байклза, Л. Сегала. М., 1974. Т. 2. С. 412-423.

15. Торлопов М.А., Фролова С.Ф., Демин В.А. Сульфатирование порошковой целлюлозы, полученной методом каталитической деструкции тетрахлоридом титана // Химия в интересах устойчивого развития. 2007. Т. 15. № 4. C. 491-496.

16. Торлопов М.А., Фролова С.Ф. Получение порошковых материалов деструкцией целлюлозы кислотами Льюиса и их модификация. II. Сульфатирование порошковых материалов, полученных деструкцией целлюлозы кислотами Льюиса // Химия растительного сырья. 2007. № 3. С. 63-67.

17. Левданский А.В., Левданский В.А., Романченко А.С., Каргин В.Ф., Кузнецов Б.Н. Изучение строения продуктов сульфатирования микрокристаллической целлюлозы хлорсульфоновой кислотой в диоксане методами РЭМ и АСМ // Техническая химия. От теории к практике : сб. ст. III Междун. конф. Пермь, 2012. С. 182-185. 
Levdansky V.A. ${ }^{1,2}$, Krylov A.S. ${ }^{3}$, Levdansky A.V. ${ }^{1}$, Bondarenko G.N. ${ }^{l}$, Kuznetsov B.N..$^{1,2^{*}}$, Romanchenko A.S. ${ }^{1}$, Mazurova E.V. ${ }^{1}$ STUDY OF PRODUCTS OF MICROCRYSTALLINE CELLULOSE SULFATION WITH CHLOROSULFONIC ACID IN DIOXANE BY FT RAMAN, XRD, SEM AND AFM METHODS

${ }^{1}$ Institute of Chemistry and Chemical Technology SB RAS, Akademgorodok, 50-24, Krasnoyarsk 660036 (Russia), e-mail: inm@icct.ru

${ }^{2}$ Siberian Federal University, pr. Svobodny, 79, Krasnoyarsk, 660041 (Russia)

${ }^{3}$ Kirensky Institute of Physics SB RAS, Akademgorodok, 50-38, Krasnoyarsk, 660036 (Russia)

Physical-chemical study of the structure of sulfated microcrystalline cellulose (MCC) obtained by oxidative delignification of wheat straw was accomplished. The substitution of OH-groups of MCC on sulfate groups after MCC treatment by chlorosufonic acid in dioxane was confirmed by Raman spectroscopy method. The decrease of MCC crystallinity degree was detected by XRD method. According to SEM and AFM data the MCC sulfates, obtained in dioxane medium have the morphology completely different from initial MCC. They consist of spherical shape particles and the surface of MCC sulfates film is formed by homogeneous spheric shape crystallites with sizes $100-150 \mathrm{~nm}$.

Keywords: microcrystalline cellulose, chlorosulfonic acid, MCC sulfates, dioxane, FT Raman spectroscopy, X-ray diffraction, scanning electron microscopy, atomic-force microscopy.

\section{References}

1. Groth T., Wagenknecht W. Biomaterials, 2001, vol. 22, issue 20, pp. 2719-2729.

2. Petropavlovskij G.A. Gidrofil'nye chastichno zameshhennye jefiry celljulozy i ih modifikacija putem himicheskogo sshivanija. [Hydrophilic partially substituted cellulose ethers and their modification by chemical crosslinking]. Leningrad, 1988, 298 p. (in Russ.)

3. Torlopov M.A, Demin V.A. Himija rastitel'nogo syr'ja, 2007, no. 3, pp. 55-61. (in Russ.)

4. Mahner C., Lechner M.D., Nordmeier E. Carbohydrate Research, 2001, vol. 331, pp. 203-208.

5. Wang Z.M., Li L, Zheng B.S., Normakhamatov N., Guo S.Y. Int. J. Biol. Macromol, 2007, vol. 41(4), pp. $376-382$.

6. Rogovin Z.A., Shorygina N.N. Himija celljulozy i ejo sputnikov. [Chemistry of cellulose and its satellites]. Moscow, 1953, 680 p. (in Russ.)

7. Wang, Z.M., Li L., Xiao K.-J., Wu J.-Y. Bioresource Technology, 2009, vol. 100, no. 4, pp. 1687-1690.

8. Levdanskij V.A., Levdanskij A.V., Kuznecov B.N. Himija rastitel'nogo syr'ja, 2012, no. 1, pp. 39-44. (in Russ.)

9. Kalinina T.B., Drozd N.N., Kuznecova S.A. and others. Gematologija i transfuziologija, 2011, vol. 56, no. 6, pp. 3338. (in Russ.)

10. Obolenskaja A.V., El'nickaja Z.P., Leonovich A.A. Laboratornye raboty po himii drevesiny i celljulozy: uchebnoe posobie dlja vuzov. [Laboratory work on the chemistry of wood and cellulose: a manual for schools]. Moscow, 1991, 320 p. (in Russ.)

11. Patent 2312110 (RU). 10.12.2007. (in Russ.)

12. Zhang K., Brendler E., Fischer S. Cellulose, 2010, vol. 17, no. 2, pp. 427-435.

13. Zhang K., Brendler E., Geissler A., Fischer S. Polymer, 2011, vol. 52, no. 1, pp. 26-32.

14. Battista O.A. Celljuloza i ee proizvodnye, Moscow, 1974, vol. 2, pp. 412-423. (in Russ.)

15. Torlopov M.A., Frolova S.F., Demin V.A. Himija v interesah ustojchivogo razvitija, 2007, vol. 15, no. 4, pp. 491496. (in Russ.)

16. Torlopov M.A., Frolova S.F. Himija rastitel'nogo syr'ja, 2007, no. 3, pp. 63-67. (in Russ.)

17. Levdanskij A.V., Levdanskij V.A., Romanchenko A.S., Kargin V.F., Kuznecov B.N. Sb. Tehnicheskaja himija. Ot teorii k praktike. [Technical chemistry from theory to practice]. Perm', 2012, pp. 182-185. (in Russ.)

Received November 14, 2013

\footnotetext{
* Corresponding author.
} 
